\title{
The Effectiveness of Silica Sand in Semi-Aerobic Stabilized Landfill Leachate Treatment
}

\section{Ezlina Othman ${ }^{1}$, Mohd Suffian Yusoff ${ }^{1, *}$, Hamidi Abdul Aziz ${ }^{1}$, Mohd Nordin Adlan ${ }^{1}$, Mohammed J. K. Bashir ${ }^{1}$ and Yung-Tse Hung ${ }^{2}$}

1 School of Civil Engineering, Engineering Campus, Universiti Sains Malaysia, 14300 Nibong Tebal, Penang, Malaysia; E-Mails: ezlinaothman@gmail.com (E.O.); cehamidi@eng.usm.my (H.A.A.); cenordin@eng.usm.my (M.N.A.); gaborbash@yahoo.com (M.J.K.B.)

2 Department of Civil and Environmental Engineering, Cleveland State University, 2121 Euclid Avenue, Cleveland, OH 44115, USA; E-Mail: yungtsehung@yahoo.com (Y.T.H.)

* Author to whom correspondence should be addressed; E-Mail: suffian@eng.usm.my; Tel: +604-5995999; Fax: +604-5941009.

Received: 10 October 2010; in revised form: 1 November 2010 / Accepted: 25 November 2010 / Published: 6 December 2010

Abstract: This study examines the suitability of natural silica sand as a low-cost adsorbent for the removal of ammoniacal nitrogen and heavy metals, particularly iron and zinc, from semi-aerobic stabilized landfill leachate. Leachate samples were collected from the Pulau Burung landfill site (PBLS) in Penang, Malaysia. The above-mentioned contaminants are highlighted in this study because of their unsafe concentrations at PBLS. The effects of shaking time, settling time, and silica sand dosage on the study parameter removal efficiencies were investigated to predict the performance of the process. The adsorptions of ammoniacal nitrogen, iron, and zinc were judiciously described by Langmuir and Freundlich isotherm models. The optimum removal efficiencies of ammoniacal nitrogen, iron, and zinc obtained were $51 \%, 44.4 \%$, and $39.2 \%$, respectively, with a shaking time of $90 \mathrm{~min}$, a settling time of $60 \mathrm{~min}$, and with a dosage of $60 \mathrm{~g}(0.5 \mathrm{~kg} / \mathrm{L})$ of silica sand. Based on the coefficient of determination $\left(R^{2}\right)$ values obtained from Langmuir and Freundlich isotherm models, ammoniacal nitrogen, iron, and zinc adsorption were better fitted to the Freundlich model.

Keywords: semi-aerobic landfill; stabilized leachate treatment; adsorption; silica sand 


\section{Introduction}

Landfill is the technique employed most worldwide for the disposal of municipal solid waste (MSW) in developing countries such as Malaysia [1-3]. After being placed in landfills, solid waste habitually decomposes through a series of combined physicochemical and biological processes. Accordingly, the decomposition of waste in combination with percolating precipitation results in the creation of an extremely polluted liquid called landfill leachate. As stated by Kurniawan and Lo [4], one metric ton of landfill MSW would generate $0.2 \mathrm{~m}^{3}$ of leachate; however, the qualities and the quantities of landfill leachate are influenced by the moisture content, site hydrology, landfill age, climatic conditions, and degree of waste stabilization [5].

Landfill leachate contains high amounts of organic compounds, ammonia, and heavy metals [6]. Thus, the generation of landfill leachate creates the potential for long-term impact on the surrounding environment. The potentiality of leachate to eventually find its way into ground/surface water creates serious hazards to public health and ecosystems. Therefore, leachate treatment remains a salient anxiety and a remarkable concern worldwide [7,8]. The leachate composition from different sanitary landfills, as mentioned by Renou et al. [9], displays wide variation. Chemical oxygen demand (COD) concentrations can vary from 100 to $70,900 \mathrm{mgL}^{-1}$, resulting in severe toxicity in many cases. The $\mathrm{BOD}_{5}$ (Biochemical Oxygen Demand)/COD ratio (from 0.70 to 0.04 ) could quickly decrease as the landfill site ages [10], showing the low efficiency of biological treatment. In addition, landfill leachate contains high amounts of ammonia that can reach up to $13,000 \mathrm{mgL}^{-1}$. Ammoniacal nitrogen has been classified as the primary source of acute toxicity when its concentration is higher than $100 \mathrm{mg} / \mathrm{L}$, as proven in [11]. The highly concentrated pollution of the leachate makes the validity of biological treatment insufficient and impermanent, particularly for stabilized leachate [9,12]. Typically, the age of landfill is a main decisive factor for the selection of an appropriate treatment technique for landfill leachate. The presence of high levels of $\mathrm{BOD}_{5}$ in young leachate makes it suitable for biological treatment. This method is known to be reliable, simple, and cost-effective [13]. In contrast, physicalchemical methods, which are not preferential for young leachate treatment, have been found to be suitable for the removal of refractory substances from old "stabilized" leachate $[9,12]$.

In most countries, environmental rules and regulations currently enforced by regulatory agencies concerning the observation and control of pollutants resulting from leachate waste streams are becoming more rigid. Imposing such rules inevitably affects the design, planning, and operation of the municipal landfills [14]. This has encouraged growing research awareness focused towards establishing an evidently important, distinctive, consistent, and durable treatment for heavily polluted leachate. Lately, an extensive variety of scientific studies, widely covering collection, storage, and suitable treatment of highly contaminated landfill leachate, has been conducted [9]. In light of the literature, adsorption [1,15], air stripping [16], membrane filtration [17], coagulation, flocculation [7], ion exchange [3,18], chemical and electrochemical oxidation methods [19-20], and chemical precipitation [21] are the major common physicochemical treatment methods for stabilized landfill leachate treatment. Among all the above-mentioned methods, adsorption can be classified as the most competent and promising fundamental approach in wastewater treatment. It is known as a surface phenomenon in which a multi-component fluid (gas or liquid) mixture is attracted to the surface of a solid adsorbent, shaping attachments via physical or chemical bonds $[8,22]$. 
In view of the above matter, adsorption via activated carbon has gained prominence in the removal of an indispensable quantity of organic substances, typically measured as COD, from the stabilized leachate. Activated carbon is well known as a typical and effective medium that can successfully remove organic substances from landfill leachate. However, the presence of a considerable amount of inorganic substances (indicated by ammoniacal nitrogen), which is difficult to effectively remove by activated carbon, has necessitated investigation into the performance efficiency of numerous low-cost available natural materials, such as zeolite and limestone, as adsorbents [1,15]. In the present study, the treatability of ammoniacal nitrogen, iron, and zinc from semi-aerobic stabilized landfill leachate via low-cost natural silica sand is investigated and documented. In addition, the equilibrium isotherms in this study are investigated and illustrated with Langmuir and Freundlich isotherms. This experiment is the first of its kind for semi-aerobic stabilized landfill leachate. The results will be thoroughly utilized as a base to investigate cheaper unconventional adsorbents for such landfills.

\section{Materials and Methods}

\subsection{Landfill Site Characteristics}

The present study focuses on the leachate generated from the Pulau Burung landfill site (PBLS). PBLS is located on the northwest coast of Peninsular Malaysia, which has a tropical climate (within the Byram Forest Reserve at $5^{\circ} 24^{\prime}$ N Latitude, $100^{\circ} 24^{\prime}$ E Longitude), approximately $20 \mathrm{~km}$ southeast of Penang Island. The total area of the landfill is 63.4 ha; nevertheless, only 33 ha are currently operational, receiving 2,200 tons of solid waste daily. This site was developed as a semi-aerobic sanitary landfill Level II by establishing a controlled tipping technique in 1991. In 2001, PBLS was upgraded to a Level III sanitary landfill by employing controlled tipping with leachate recirculation. In Malaysia, the level of improvement of sanitary landfill system can be achieved in four stages [23]:

Level I: Controlled tipping

Level II: Sanitary landfill with a bund (embankment) and daily soil covering

Level III: Sanitary landfill with a leachate recirculation system

Level IV: Sanitary landfill with leachate treatment facilities

\subsection{Sampling}

Leachate samples were collected manually $(10 \mathrm{~L}$ per sample) monthly from the aeration pond at PBLS from January to April 2009. In accordance with the Standard Method of Water and Wastewater Examination, the samples were immediately transported to the USM Environmental Engineering Laboratory. The samples were preserved in a cold room at $4{ }^{\circ} \mathrm{C}$ prior to experimental use in order to minimize biological and chemical reactions. All chemical analyses for leachate characterization were carried out within the following $24 \mathrm{~h}$. The samples were analyzed for ammoniacal nitrogen, iron, and zinc according to Standard Methods for the Examination of Water and Wastewater [24].

\subsection{Silica Sand Properties}

Natural raw silica sand was taken from the former mining site in Serdang, Kedah, Malaysia. The raw silica sand was washed repeatedly to remove impurities, roots, leaves, and soils, and then air-dried 
under sunlight. Subsequently, it was sieved to $0.6-1.18 \mathrm{~mm}$ particle size. After drying, the chemical composition of the silica sand was determined by x-ray fluorescence (Rigaku RIX3000), as illustrated in Table 1. The physical properties of the silica sand applied in this study are provided in Table 2. The density of silica sand was measured by gas pyrometer test (Micromeritics AccuPyc 1330). Brunauer-Emmett-Teller method using the Micromeritics FlowSorb II 2300 was used to determine the specific surface area (total area available for adsorption).

Table 1. Chemical composition of silica sand.

\begin{tabular}{|c|c|c|c|}
\hline Composition & $\begin{array}{l}\text { Results } \\
(\%)\end{array}$ & Composition & $\begin{array}{l}\text { Results } \\
(\%)\end{array}$ \\
\hline $\mathrm{SiO}_{2}$ & 92.214 & $\mathrm{Fe}_{2} \mathrm{O}_{3}$ & 0.236 \\
\hline $\mathrm{Al}_{2} \mathrm{O}_{3}$ & 5.848 & $\mathrm{SO}_{3}$ & 0.013 \\
\hline $\mathrm{K}_{2} \mathrm{O}$ & 1.382 & $\mathrm{Rb}_{2} \mathrm{O}$ & 0.010 \\
\hline $\mathrm{MgO}$ & 0.088 & $\mathrm{ZrO}_{2}$ & 0.007 \\
\hline $\mathrm{Na}_{2} \mathrm{O}$ & 0.071 & $\mathrm{NiO}$ & 0.004 \\
\hline $\mathrm{TiO}_{2}$ & 0.051 & $\mathrm{ZnO}$ & 0.002 \\
\hline $\mathrm{CaO}$ & 0.040 & $\mathrm{CuO}$ & 0.001 \\
\hline $\mathrm{P}_{2} \mathrm{O}_{5}$ & 0.032 & & \\
\hline
\end{tabular}

Table 2. Physical characteristics of silica sand.

\begin{tabular}{lc}
\hline Type of test & Result \\
\hline Surface area,$\left(\mathrm{m}^{2} / \mathrm{g}\right)$ & 0.33 \\
Density, $\left(\mathrm{kg} / \mathrm{m}^{3}\right)$ & 2510 \\
Void ratio, $(\%)$ & 50 \\
Particle size, $(\mathrm{mm})$ & $0.60-1.18$ \\
\hline
\end{tabular}

\subsection{Experimental Conditions}

In this study, a series of batch experiments were carried out in order to determine the optimum experimental conditions to achieve the maximum removal efficiency of $\mathrm{NH}_{3}-\mathrm{N}$, iron and zinc. All experiments were conducted by shaking $120 \mathrm{~mL}$ of raw leachate with a specific amount of silica sand in a $250 \mathrm{~mL}$ conical flask at a shaking speed of $350 \mathrm{rpm}$ using an orbital shaker (model PROTECH 720, Malaysia). The influence of shaking time, settling time and silica sand dosage on the removal parameters was examined. The influence of the shaking time was initially evaluated by running the experiments for many consecutive times for different durations (30, 60, 90, and 120 min), with a shaking speed of $350 \mathrm{rpm}$, settling time of $2 \mathrm{~h}$ and silica sand dosage of $40 \mathrm{~g}(333 \mathrm{~g} / \mathrm{L})$. The experiments were repeated to determine the settling time by allowing samples to settle for different durations $(30,60,90$, and $120 \mathrm{~min})$ using the results of the shaking time tests. Afterward, the results of shaking time and settling time were used as constant conditions for evaluating the influence of silica sand dosage, in which different dosages i.e., 20, 40, 60, 80, and $100 \mathrm{~g}$ (to be precise, 166, 333, 500, 666 , and $833 \mathrm{~g} / \mathrm{L}$ ) were tested. After each run, the percentages of $\mathrm{NH}_{3}-\mathrm{N}$, iron and zinc removal were measured. 


\subsection{Absorption Isotherms}

The amount of adsorption at equilibrium state, $q_{\mathrm{e}}\left(\mathrm{mg} \mathrm{L}^{-1}\right)$, was calculated by the following equation:

$$
q_{e}=\frac{\left(C_{o}-C_{e}\right) V}{W}
$$

where $C_{\mathrm{o}}$ and $C_{\mathrm{e}}\left(\mathrm{mg} \mathrm{L}^{-1}\right)$ are the liquid-phase concentrations of the sample at initial and equilibrium, respectively, $W(\mathrm{~g})$ is the mass of composite media used, and $V(\mathrm{~L})$ is the volume of the solution. Langmuir and Freundlich, the most common isotherm models, were employed in this study. According to Benefield et al. [25], the Langmuir isotherm is based on the assumption that the adsorbed layer will be one thick (homogeneous) molecule, whereas the Freundlich isotherm assumes that the adsorbent has a heterogeneous surface composed of different classes of adsorption sites.

The Langmuir isotherm linear equation is represented by the following equation:

$$
\frac{1}{q_{e}}=\frac{1}{K_{a} q_{m} C_{e}}+\frac{1}{q_{m}}
$$

The Freundlich isotherm linear equation is commonly represented by the following equation:

$$
\log q_{e}=\log K_{F}+\frac{1}{n} \log C_{e}
$$

The Langmuir constants $q_{\mathrm{m}}(\mathrm{mg} / \mathrm{g})$ and $K_{\mathrm{a}}(\mathrm{L} / \mathrm{mg})$ are related to maximum adsorption capacity and energy of adsorption, respectively, whereas $K_{\mathrm{F}}(\mathrm{mg} / \mathrm{g})(\mathrm{L} / \mathrm{mg})^{1 / n}$ and $1 / n$ are Freundlich constants related to adsorption capacity and adsorption intensity of the adsorbent, respectively.

\section{Result and Discussion}

\subsection{Pulau Burung Leachate Characteristics}

Table 3 illustrates the characteristics of the leachate at PBLS. The table indicates that ammoniacal nitrogen, iron, zinc $\mathrm{COD}$, color, and $\mathrm{BOD}_{5}$ were present in sizeable quantities with great concentrations of approximately 2,090 mg/L, $7.2 \mathrm{mg} / \mathrm{L}, 4.7 \mathrm{mg} / \mathrm{L}, 3,333 \mathrm{mg} / \mathrm{L}, 3,066 \mathrm{Pt}-\mathrm{Co}$, and $305 \mathrm{mg} / \mathrm{L}$, respectively. Pulau Burung landfill leachate is categorized to be in the phase of methane fermentation, which can be considered as stabilized leachate [5]. In this phase, the high concentrations of color and COD are mainly contributed by dissolved organic substances; however, the presence of high amounts of $\mathrm{NH}_{3}-\mathrm{N}$ are attributed to the degradation of nitrogenous compounds present in the dumped solid wastes. In general, ammonia represents the major form of nitrogen in stabilized leachate, constituting over $70 \%$ of the Total Kjeldahl Nitrogen (TKN). Zouboulis et al. [26] reported that the elevated $\mathrm{pH}$ values (7.3-8.8) of stabilized (old) leachate result in an inevitable reduction in the solubility of metals. Also, low metal content could be attributed to adsorption and precipitation processes involving the co-existing sulfides, carbonates, or hydroxide anions. The characteristics of stabilized landfill leachate are extremely different from those of domestic wastewater. Consequently, stabilized leachate is more similar to heavily contaminated industrial wastewaters, indicating that biodegradation processes are not efficient for treatment of such leachate. 
Table 3. Characteristics of the leachate at the Pulau Burung landfill site (PBLS).

\begin{tabular}{lccccc}
\hline Parameter & Minimum & Maximum & Average & $\begin{array}{c}\text { Standard } \\
\text { Deviation }\end{array}$ & $\begin{array}{c}\text { Standard } \\
\text { Discharge Limit }^{\mathbf{1}^{1}}\end{array}$ \\
\hline $\mathrm{pH}$ & 8.20 & 8.31 & 8.26 & 0.05 & $6.0-9.0$ \\
Ammoniacal nitrogen, (mg/L) & 2010 & 2090 & 2050 & 39.66 & 5.0 \\
Iron (mg/L) & 3.5 & 7.2 & 5.3 & 1.60 & 5.0 \\
Zinc (mg/L) & 2.3 & 4.6 & 3.4 & 0.95 & 2.0 \\
Copper (mg/L) & 0.40 & 0.70 & 0.55 & 0.13 & 0.2 \\
Manganese (mg/L) & 0.20 & 0.30 & 0.23 & 0.05 & 0.2 \\
Nickel (mg/L) & 0.20 & 0.40 & 0.28 & 0.09 & 0.2 \\
Lead (mg/L) & 0.20 & 0.40 & 0.32 & 0.09 & 0.1 \\
COD (mg/L) & 3027 & 3333 & 3180 & 142.93 & 400 \\
Color (Platinum unit, Pt-Co) & 2800 & 3066 & 2933 & 116.12 & 100 \\
BOD $(\mathrm{mg} / \mathrm{L})$ & 157 & 305 & 231 & 64.56 & 20 \\
Suspended solids (mg/L) & 70 & 190 & 130 & 50.57 & 50 \\
\hline
\end{tabular}

${ }^{1}$ Environmental Quality (Control of Pollution from Solid Waste Transfer Station and Landfill)

Regulations 2009, under the Laws of Malaysia-Malaysia Environmental Quality Act 1974 [27].

\subsection{Optimum Conditions}

The optimization of the media performance was achieved by monitoring the influence of one factor at a time on experimental response. This optimization is called the one-variable-at-a-time method. Where only one variable is varied, the others are maintained at a constant level [28]. Figures 1 to 3 demonstrate the experimental results for determining the optimum shaking time, settling time, and silica sand dosage, respectively. The figures also illustrate the influence of each factor on ammoniacal nitrogen, iron, zinc removal efficiency, and $\mathrm{pH}$. As noted in Figure 1, more than 44\% of ammoniacal nitrogen, $42 \%$ of iron, and $38 \%$ of zinc removal was obtained with an optimal shaking time of 90 min, and a settling time of $120 \mathrm{~min}$, shaking speed of $350 \mathrm{rpm}$, and silica sand dosage of $40 \mathrm{~g}(333 \mathrm{~g} / \mathrm{L})$. As shown in Figure 1, shaking time has a great influence on the parameter removal efficiency; sufficient shaking time is necessary to achieve excellent adsorption of pollutants. Figure 2 shows that the parameter removal increased with increasing settling time up to $60 \mathrm{~min}$, and then remained constant. In fact, the improved removal efficiency at higher agitation speed and with a longer shaking time is due to the rigorous mixing and longer solid-liquid contact bringing about improved interaction between the silica sand and the leachate. The influence of silica sand dosage on the parameter removal efficiencies is shown in Figure 3. Approximately $50.9 \%, 44.4 \%$, and $39.2 \%$ of ammoniacal nitrogen, iron, and zinc, respectively, were removed when $60 \mathrm{~g}(0.5 \mathrm{~kg} / \mathrm{L})$ of silica sand was used (Figure 3). However, with this silica sand dosage, the $\mathrm{pH}$ of the treated effluent ranged from 3 to 4 , indicating that $\mathrm{pH}$ adjustment is strongly required before effluent discharge in order to comply with the Malaysian standard discharge limit. In general, the precipitation of solids increased at lower pH values [29]. Kadirvelu and Namasivayam [30] reported that the removal of iron under acidic conditions was better than under alkaline conditions. Based on the results, the performance of silica sand was shown to be better than activated carbon in terms of $\mathrm{NH}_{3}-\mathrm{N}$ removal efficiency from landfill leachate. Whereas approximately $40 \%$ of $\mathrm{NH}_{3}-\mathrm{N}$ with an initial concentration of more than $1,000 \mathrm{mg} / \mathrm{L}$ can be removed by either activated carbon or a mixture of carbon with limestone at a mixture ratio of 5:35 [31], more 
than $92 \%$ removal of $\mathrm{NH}_{3}-\mathrm{N}$ can be achieved by employing an ion exchange technique [3]. The ion exchange process appears to be an efficient method among the physicochemical processes for removal of inorganic substances from landfill leachate. However, a considerable disadvantage hindering the success of ion exchange is the high cost of ion exchange resin compared to silica sand.

Figure 1. Influence of shaking time on ammoniacal nitrogen, iron and zinc removal efficiency (dosage $=40 \mathrm{~g}$; shaking speed $=350 \mathrm{rpm}$; settling time $=120 \mathrm{~min}$ ).

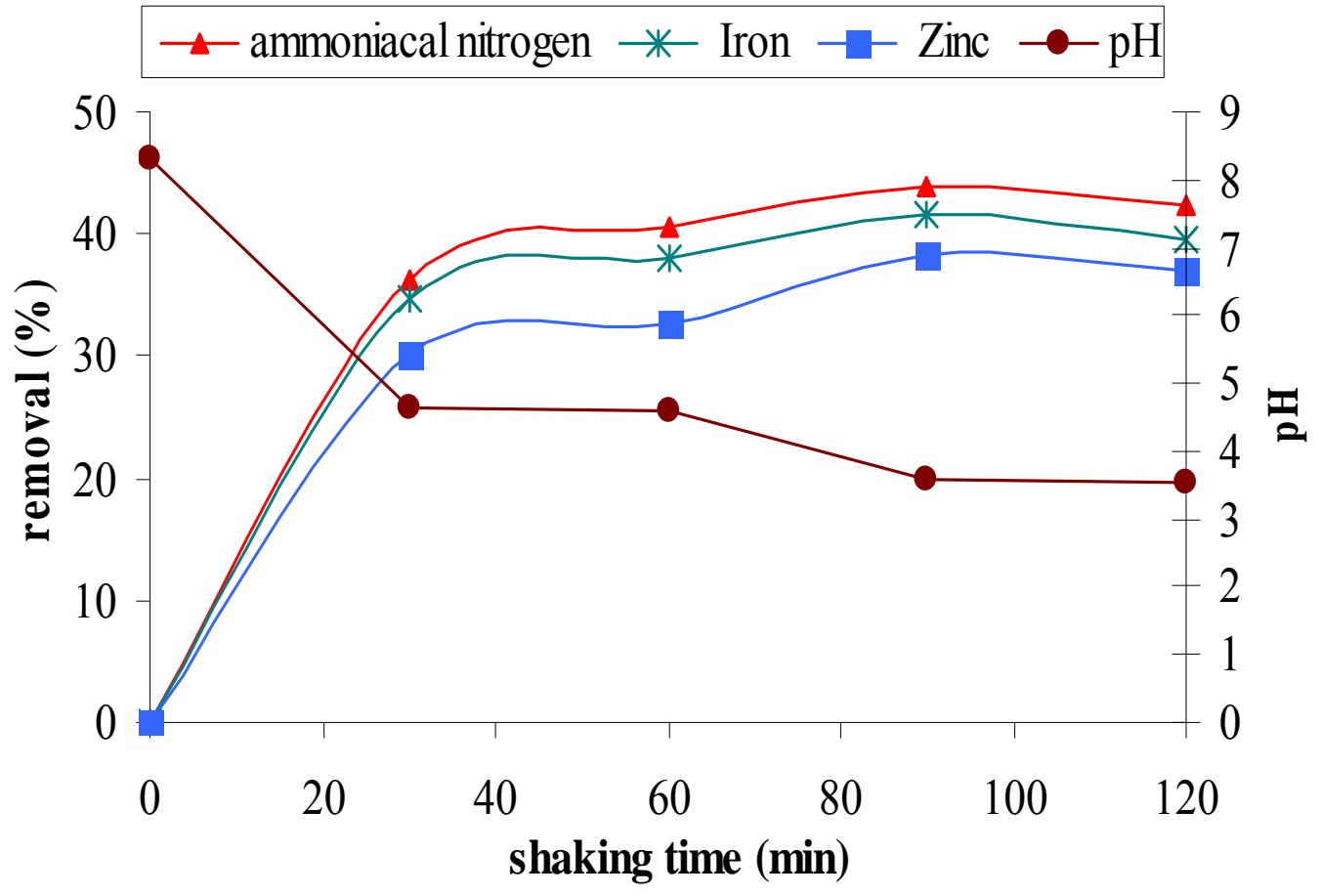

Figure 2. Influence of settling time on ammoniacal nitrogen, iron and zinc removal efficiency $($ dosage $=40 \mathrm{~g}$; shaking speed $=350 \mathrm{rpm}$; shaking time $=90 \mathrm{~min})$.

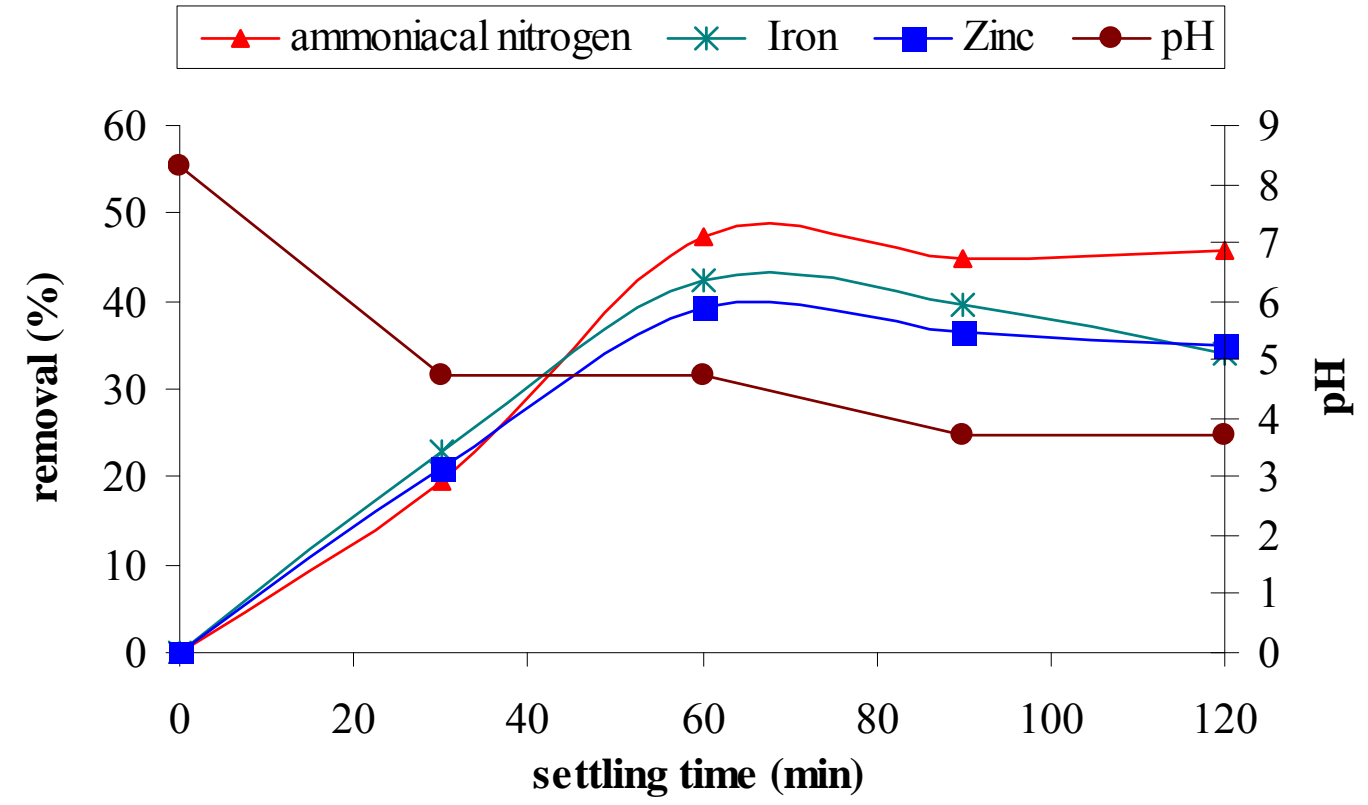


Figure 3. Influence of silica sand dosage on ammoniacal nitrogen, iron and zinc removal efficiency (shaking speed $=350 \mathrm{rpm}$; shaking time $=90 \mathrm{~min}$; settling time $=60 \mathrm{~min}$ ).

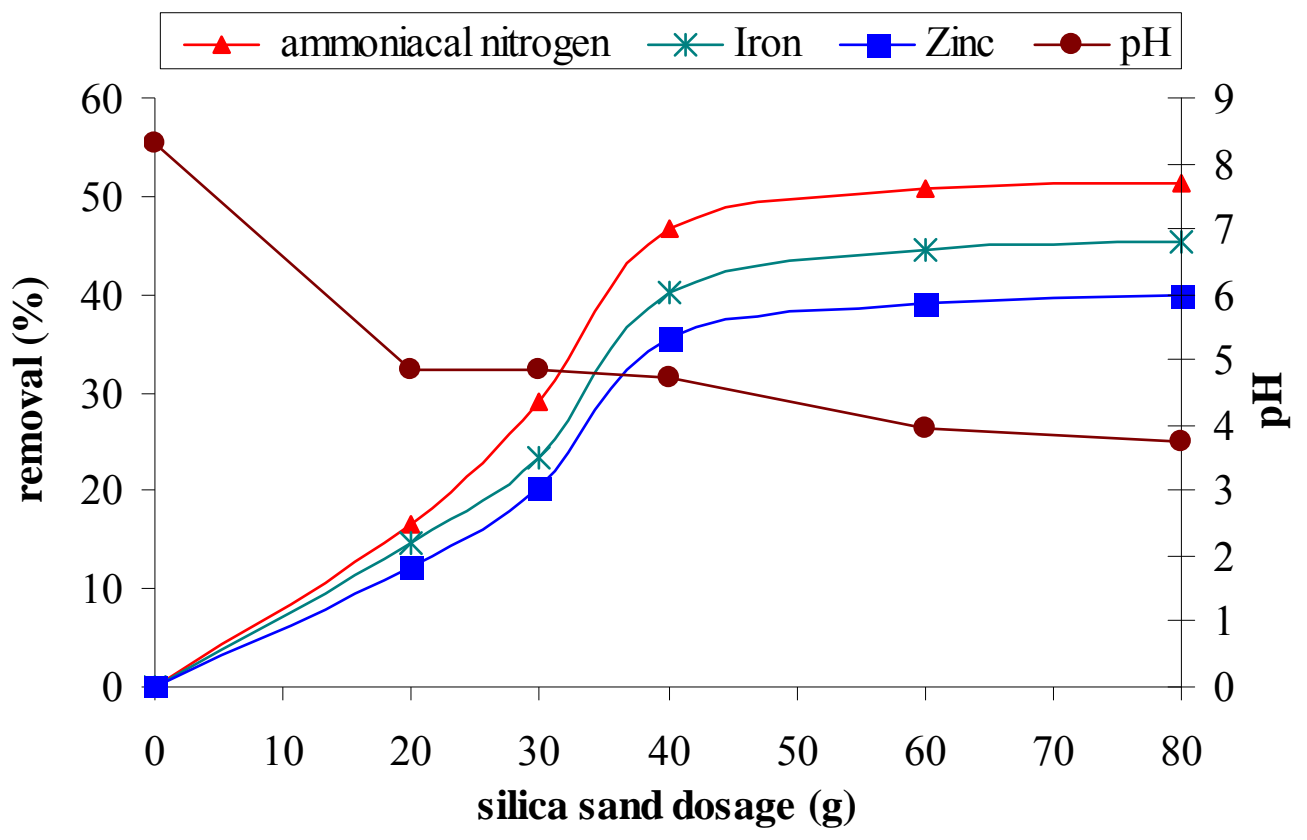

\subsection{Adsorption Isotherms}

Langmuir and Freundlich adsorption isotherm models, which have been profitably applied to many adsorption processes [1,15], were used to study the silica sand adsorption behavior. Figures 4 to 6 show the linear plot of Langmuir and Freundlich isotherms for the adsorption of ammoniacal nitrogen, iron, and zinc, respectively, onto silica sand.

Figure 4. Adsorption isotherm for ammoniacal nitrogen onto silica sand: (a) Langmuir, and (b) Freundlich.

(a)

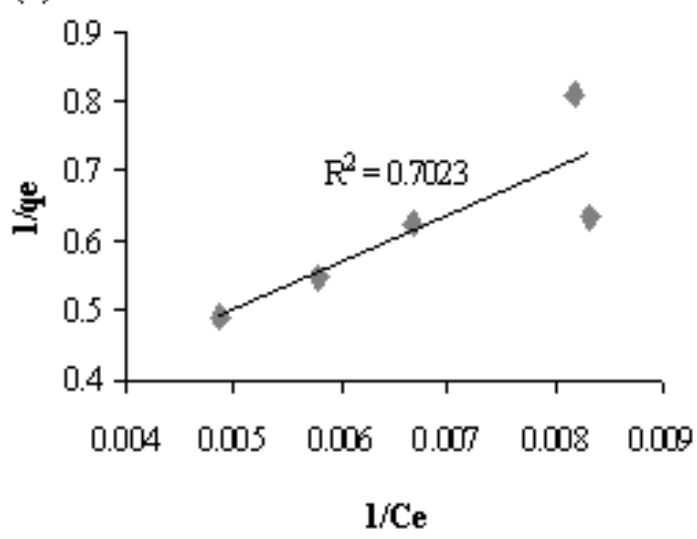

(b)

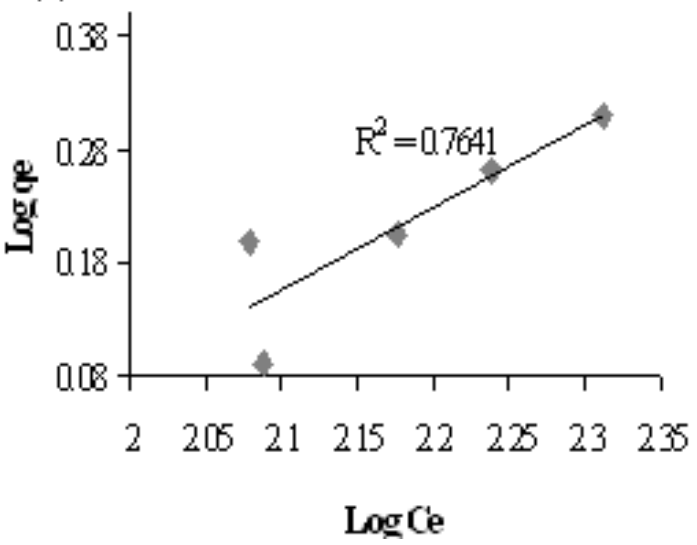


Figure 5. Adsorption isotherm for iron onto silica sand: (a) Langmuir, and (b) Freundlich.

(a)

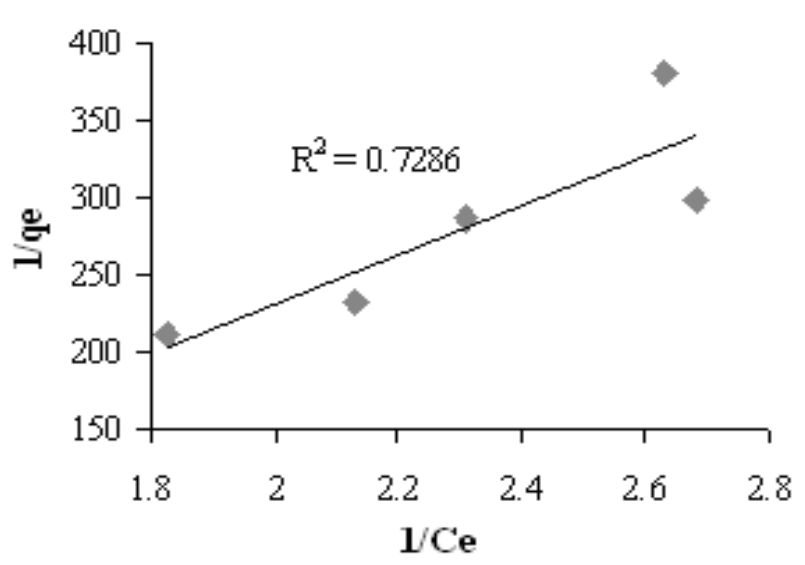

(b)

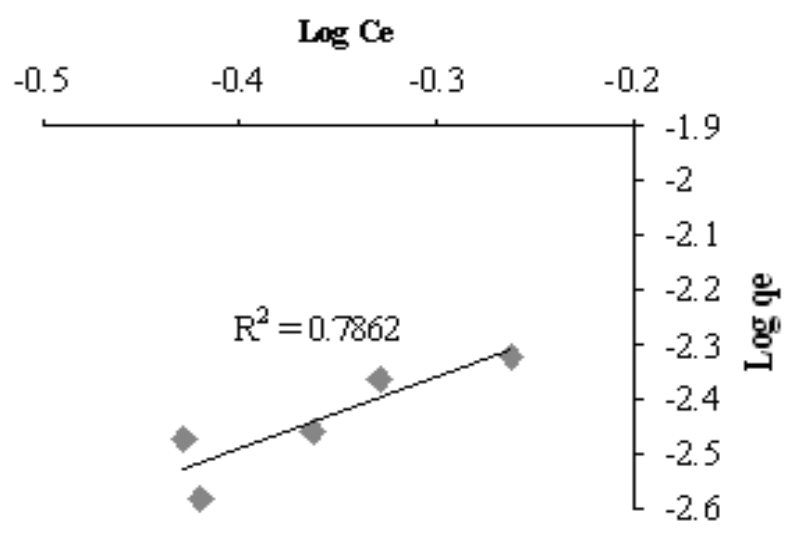

Figure 6. Adsorption isotherm for zinc onto silica sand at: (a) Langmuir and (b) Freundlich.

(a)

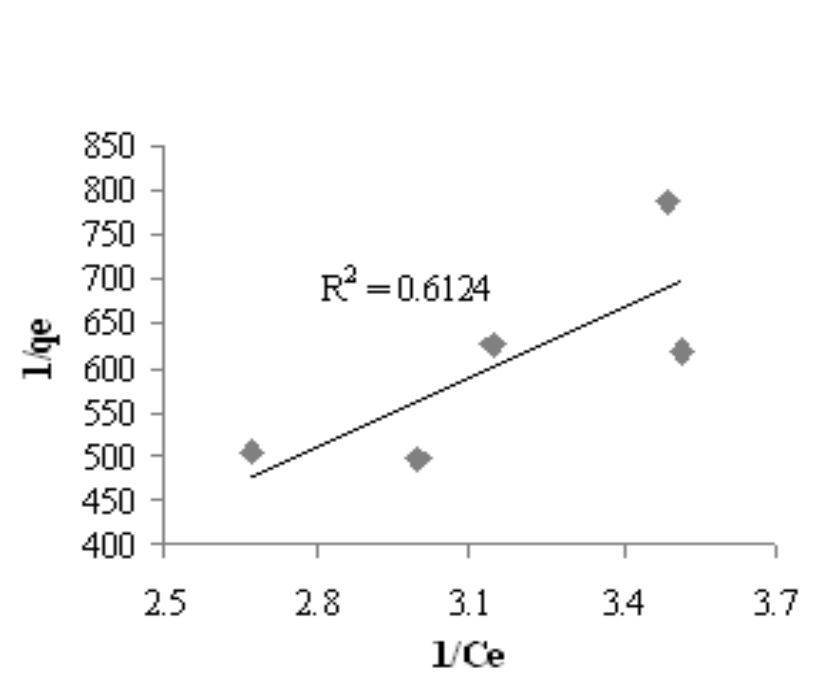

(b)

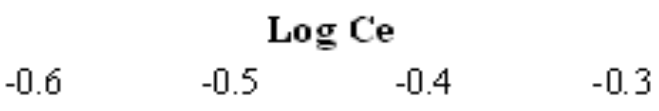

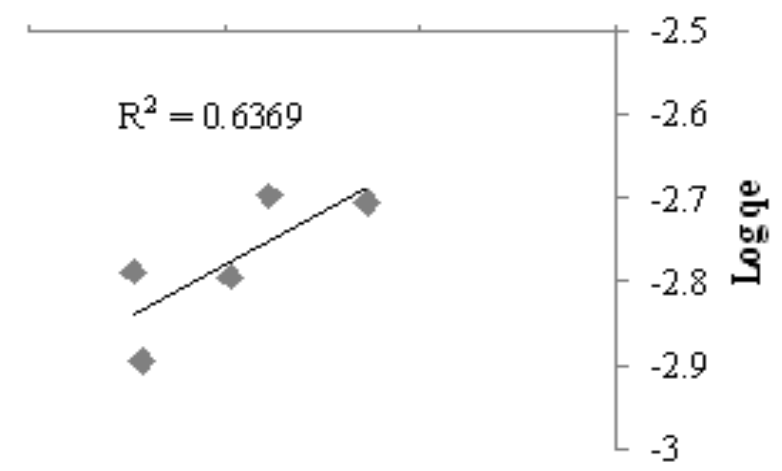

The empirical constant values of Langmuir and Freundlich isotherms were calculated from the linear plot illustrated in Table 4. As shown in Table 4, the maximum monolayer adsorptions of $\mathrm{NH}_{3}-\mathrm{N}$, iron, and zinc onto silica sand were $6.097,0.0109$, and $0.0046 \mathrm{mg} / \mathrm{g}$, respectively. The coefficient of determination $\left(R^{2}\right)$ was $0.702,0.728$, and 0.612 for ammoniacal nitrogen, iron, and zinc, respectively.

Table 4. Langmuir and Freundlich isotherm constants for adsorption of ammoniacal nitrogen, iron and zinc onto silica sand.

\begin{tabular}{lllllll}
\hline Adsorbate & \multicolumn{2}{l}{ Langmuir } & \multicolumn{3}{c}{ Freundlich } \\
& $\mathbf{Q}(\mathbf{m g} / \mathbf{g})$ & $\mathbf{b}(\mathbf{L} / \mathbf{m g})$ & $\mathbf{R}^{\mathbf{2}}$ & $\boldsymbol{* K}_{\mathbf{F}}$ & $\mathbf{1 / n}$ & $\mathbf{R}^{\mathbf{2}}$ \\
\hline Ammoniacal-nitrogen & 6.0975 & 0.00243 & 0.702 & 0.04426 & 0.719 & 0.764 \\
Iron & 0.0109 & 0.56574 & 0.728 & 0.0107 & 1.305 & 0.786 \\
Zinc & 0.0046 & 0.82729 & 0.612 & 0.00752 & 1.309 & 0.636 \\
\hline
\end{tabular}


The characteristics of Langmuir isotherm can be explained by using a dimensionless equilibrium parameter $\left(R_{L}\right)$, by using the following equation:

$$
R_{L}=\frac{1}{1+b C_{0}}
$$

where $b$ is the Langmuir constant and $C_{0}$ is the initial parameter concentration $(\mathrm{mg} / \mathrm{L})$. This equation denotes the value of $R_{\mathrm{L}}$, which indicates whether the isotherm is favorable $\left(0<R_{\mathrm{L}}<1\right)$, unfavorable $\left(R_{\mathrm{L}}>1\right)$, linear $\left(R_{\mathrm{L}}=1\right)$, or irreversible $\left(R_{\mathrm{L}}=0\right)$. By using this equation, the $R_{\mathrm{L}}$ values for ammoniacal nitrogen, iron, and zinc are shown to be in the range of 0 to 1 . Consequently, the results indicate that the Langmuir isotherm is favorable for this study. In light of Table 4, the constant $R^{2}$ values obtained using the Freundlich isotherm model for ammoniacal nitrogen, iron, and zinc were $0.764,0.786$, and 0.636. The constant $1 / n$ functions as the strength of the adsorbent. The value of $1 / n$ closer to 1 has a high adsorption bond; however, high values of $1 / n>1$ show that the adsorption bond is weak [28]. This means that the value of $q_{\mathrm{e}}$ consumes large dosages for a small change in $C_{\mathrm{e}}$. In this study, the values of $1 / n$ for ammoniacal nitrogen, iron, and zinc were $0.719,1.305$, and 1.309, respectively. Aziz et al. [32] reported that when $1 / n>1$, the sorption constant grows with the increasing concentration of solution. According to the observed $R^{2}$ values obtained from the Langmuir and Freundlich isotherm models, the Freundlich isotherm proved to be a better fit for adsorption because all the $R^{2}$ values were higher than those obtained from the Langmuir isotherm.

\section{Conclusions}

In this study, the adsorption efficiency of ammoniacal nitrogen, iron, and zinc from the semi-aerobic stabilized landfill leachate via natural silica sand as a low-cost adsorbent was investigated. Based on the experimental results, the optimum conditions for batch adsorption were established to be $90 \mathrm{~min}$ of contact time, $60 \mathrm{~min}$ of settling time, and a shaking speed of $350 \mathrm{rpm}$. Both Langmuir and Freundlich isotherm studies exhibited that silica sand shows favorable adsorption for the removal of ammonia nitrogen, iron, and zinc in semi-aerobic stabilized landfill leachate. In accordance with the coefficient of determination, ammoniacal nitrogen, iron, and zinc adsorption was better fitted to the Freundlich model. The results indicate that silica sand is potentially efficient as an alternative low-cost adsorbent for stabilized leachate treatment. However, in light of its insufficient effectiveness in terms of removal of all pollutants present in stabilized leachate, particularly organic substances, silica sand can more effectively be used as a filter medium in a preliminarily treatment stage prior to more efficient physicochemical processes.

\section{References}

1. Aziz, H.A.; Foul, A.A.; Isa, M.H.; Hung, Y-T. Physico-chemical treatment of anaerobic landfill leachate using activated carbon and zeolite: Batch and column studies. Int. J. Environ. Waste Manage. 2010, 5, 269-285.

2. Omran, A.; El-Amrouni, A.O.; Suliman, L.K.; Pakir, A.H.; Ramli, M.; Aziz, H.A. Solid waste management practices in Penang State: A review of current practices and the way forward. Environ. Eng. Manage. J. 2009, 8, 97-106. 
3. Bashir, M.J.K.; Aziz, H.A.; Yusoff, M.S.; Huqe, A.A.M.; Mohajeri, S. Effects of ion exchange resins in different mobile ion forms on semi-aerobic landfill leachate treatment. Water Sci. Technol. 2010, 61, 641-649

4. Kurniawan, T.A.; Lo, W.H. Removal of refractory compounds from stabilized landfill leachate using an integrated $\mathrm{H}_{2} \mathrm{O}_{2}$ oxidation and granular activated carbon (GAC) adsorption treatment. Water Res. 2009, 43, 4079-4091.

5. Tchobanouglos, G.; Theisen, H.; Vigil, S.A. Integrated Solid Waste Management: Engineering Principles and Management Issues; McGraw-Hill, Inc.: New York, NY, USA, 1993.

6. Christensen, T.H.; Kjeldsen, P.; Bjerg, P.L.; Jensen, D.L.; Christensen, J.B.; Baun, A.; Albrechtsen, H-J.; Heron, G. Biogeochemistry of landfill leachate plumes. Appl. Geochem. 2001, 16, 659-718.

7. Ghafari, S.; Aziz, H.A.; Bashir, M.J.K. The use of poly-aluminum chloride and alum for the treatment of partially stabilized leachate: Acomparative study. Desalination 2010, 257, 110-116.

8. Foo, K.Y.; Hameed, B.H. An overview of landfill leachate treatment via activated carbon adsorption process. J. Hazard. Mater. 2009, 171, 54-60

9. Renou, S.; Givaudan, J.G.; Poulain, S.; Dirassouyan, F.; Moulin, P. Landfill leachate treatment: review and opportunity. J. Hazard. Mater. 2008, 150, 468-493.

10. Chian, E.S.K.; DeWalle, F.B. Sanitary landfill leachates and their treatment. J. Environ. Eng. Div. 1976, 45, 411-431.

11. Silva, A.C.; Dezotti, M.; Sant'Anna, G.L., Jr. Treatment and detoxification of a sanitary landfill leachate. Chemosphere 2004, 55, 207-214.

12. Kurniawan, T.A.; Lo, W.H.; Chan, G.Y.S. Physico-chemical treatments for removal of recalcitrant contaminants from landfill leachate. J. Hazard. Mater. 2006, 129, 80-100.

13. Uygur, A.; Kargi, F. Biological nutrient removal frompre-treated landfill leachate in a sequencing batch reactor. J. Environ. Manage. 2004, 71, 9-14.

14. Hansen, W.M.; Christopher, M.; Verbuecheln, M. EU Waste Policy and Challenges for Regional and Local Authorities; Ecological Institute for International and European Environmental Policy: Berlin, Germany, 2002.

15. Foul, A.A.; Aziz, H.A.; Isa, M.H.; Hung, Y.-T. Primary treatment of anaerobic landfill leachate using activated carbon and limestone: batch and column studies. Int. J. Environ. Waste Manage. 2009, 4, 282-298.

16. Cheung, K.C.; Chu, L.M.; Wong, M.H. Ammonia stripping as a pre-treatment for landfill leachate. Water Air Soil Pollut. 1997, 94, 209-221.

17. Tsilogeorgisa, J.; Zouboulisa, A.; Samarasb, P.; Zamboulisa, D. Application of a membrane sequencing batch reactor for landfill leachate treatment. Desalination 2008, 221, 483-493.

18. Bashir, M.J.K.; Aziz, H.A.; Yusoff, M.S.; Adlan, M.N. Application of response surface methodology (RSM) for optimization of ammoniacal nitrogen removal from semi-aerobic landfill leachate using ion exchange resin. Desalination 2010, 254, 154-161.

19. Mohajeri, S.; Aziz, H.A.; Isa, M.H.; Bashir, M.J.K.; Mohajeri, L.; Adlan, M.N. Influence of Fenton reagent oxidation on mineralization and decolorization of municipal landfill leachate. $J$. Environ. Sci. Health, Part A 2010, 45, 692-698. 
20. Bashir, M.J.K.; Isa, M.H.; Kutty, S.R.M.; Awang, Z.B.; Aziz, H.A.; Mohajeri, S.; Farooqi, I.H. Landfill leachate treatment by electrochemical oxidation. Waste Manage. 2009, 29, 2534-2541.

21. Kabdasli, I.; Safak, A.; Tunay, O. Bench-scale evaluation of treatment schemes incorporating struvite precipitation for young landfill leachate. Waste Manage. 2008, 28, 2386-2392.

22. Daifullah, A.; Girgis, B.; Gad, H. A study of the factors affecting the removal of humic acid by activated carbon prepared from biomass material. Colloid. Surface. A 2004, 235, 1-10.

23. Agamuthu, P. Solid Waste: Principles and Management; University of Malaya: Kuala Lumpur, Malaysia, 2001.

24. APHA (American Public Health Association), AWWA (American Water Works Association) and WPCF (Water Pollution Control Federation). Standard Methods for the Examination of Water and Wastewater, 21th ed.; APHA: Washington, DC, USA, 2005.

25. Benefield, L.D.; Judkins, J.F.; Weand, B.L. Process Chemistry for Water and Wastewater Treatment; Prentice Hall, Inc.: Englewood Cliffs, NJ, USA, 1982.

26. Zouboulis, A.I.; Ntampou, X.; Samaras, P. Characterisation and treatment of leachates from the municipal sanitary landfill of Thessaloniki, Greece. Int. J. Environ. Waste Manage. 2009, 4, 385-398.

27. Environmental Quality (Control of Pollution from Solid Waste Transfer Station and Landfill) Regulations 2009; Under the Laws of Malaysia-Malaysia Environmental Quality Act 1974; Department Of Environment: Kuala Lumpur, Malaysia, 2010.

28. Bezerra, M.A.; Santelli, R.E.; Oliveira, E.P.; Villar, L.S.; Escaleira L.A. Response surface methodology (RSM) as a tool for optimization in analytical chemistry. Talanta 2008, 76, 965-977.

29. Rodriguez, J.; Castrillon, L.; Maranon, E.; Sastre, H.; Fernandez, E. Removal of nonbiodegradable organic matter from landfill leachates by adsorption. Water Res. 2004, 38, 3297-3303.

30. Kadirvelu, K.; Namasivayam, C. Activated carbon from coconut coir pith as metal adsorbent: adsorption of Cd (II) from aqueous solution. Adv. Environ. Res. 2002, 7, 471-478.

31. Aziz, H.A.; Adlan, M.N.; Zahari, M.S.M.; Alias, S. Removal of ammoniacal-nitrogen (N-NH3) from municipal solid waste leachate by using activated carbon and lime stone. Waste Manage. Res. 2004, 22, 371-375.

32. Aziz, H.A.; Yusoff, M.S.; Adlan, M.N.; Adnan, N.H.; Alias, S. Physico-chemical removal of iron from semi-aerobic landfill leachate by limestone filter. Waste Manage. 2004, 24, 353-358.

(C) 2010 by the authors; licensee MDPI, Basel, Switzerland. This article is an open access article distributed under the terms and conditions of the Creative Commons Attribution license (http://creativecommons.org/licenses/by/3.0/). 